\title{
POR UMA EDUCAÇÃO MATEMÁTICA CRÍTICA NA EJA: DA DESOPRESSÃO À CONSCIENTIZAÇÃO DO ALUNO-CIDADÃO- CONSUMIDOR
}

\author{
FOR A CRITIC MATHEMATICS EDUCATION ON THE ADULT EDUCATION: FROM \\ UNOPRESSION TO AWARENESS OF THE STUDENT-CITIZEN-CONSUMER
}

\author{
Ricardo Moura dos Santos Marques, Christine Sertã da Costa \\ Colégio Pedro II \\ E-mail: marques.educacao@yahoo.com.br, cserta@globo.com
}

\begin{abstract}
Resumo
Foi buscando apresentar a teoria da Educação Matemática Crítica como caminho para um ensino transformador e significativo na escola da EJA que o presente texto foi construído. Trata-se de um diálogo entre teorias e referenciais levantados em uma pesquisa de mestrado que investiga o ensino de Matemática nesta modalidade da Educação Básica. Para alocar a importância da Educação Matemática Crítica (EMC) nessas reflexões, evoca-se o já conhecido debate sobre as visões excludente e libertadora da escola. Nesta última, segue-se o pensamento de Paulo Freire sobre a Pedagogia do Oprimido como possibilidade de redefinir a posição dos sujeitos sociais envolvidos nas relações educativas. É o caráter libertador e democrático da Educação Matemática Crítica que ampliará as intervenções do aluno adulto no mundo em que vive (tão abastecido de informações quantitativas), elevando-o a uma nova condição de cidadania, trabalho e consumo.
\end{abstract}

Palavras-chave: educação matemática crítica. educação de jovens e adultos. opressão. conscientização.

\begin{abstract}
The following text was created to present the theory of Critic Mathematics Education as a way to a transformative and significant education at the Adult and Youngster School. It is a dialogue between theories and references gathered by a master's degree research that investigates Mathematics teaching in this modality of education. School's exclusionary vision is argued - and Traditional Mathematics Education's - that determines the one who is not a part of the dominant minority class the education to keep being manipulated mass and oppressed by hegemonic forces. In contrast, is brought the freeing dimension of school - followed by Freire's theory - as possibility to reset the position of social subjects. It's the democratic and freeing character of Critic Mathematics Education that will widen the interventions from the adult student in the world he lives (full of quantitative information), raising him to a new condition of citizenship, work and consumption.
\end{abstract}

Keywords: critic mathematics education. adult and youngster education. oppression. awareness. 


\section{INTRODUÇÃO}

Em dias atuais, frente às responsabilidades atribuídas à escola enquanto núcleo de formação e qualificação para a cidadania, surge uma urgente e pertinente questão: como educar para um mundo cada vez mais abastecido por técnicas, estímulos de consumo e dados quantitativos?

A questão é profunda e complexa pois, ao pensar o como, justifica-se a postura da escola na relação com o conhecimento, deixando à interpretação a dimensão de ser ou não um espaço democrático. Afinal, quem está sendo preparado para o novo mundo: todos ou grupos específicos?

A pergunta denuncia a visão discriminatória da Escola que surge, neste trabalho, não como condenação, mas como status para alocar um contraponto: a possibilidade transformadora de sua atividade social - foco das reflexões. De fato, a escola não é neutra, estando envolvida no conjunto da atividade política da sociedade [...] (CORTELLA, 2000).

Este texto é construído a partir de fragmentos e reflexões de uma pesquisa de mestrado intitulada Matemática Cotidiana: Um Trabalho com Matemática Crítica na Educação de Jovens e Adultos, desenvolvida no ano de 2014.

Em um primeiro momento, discutiremos as desigualdades educacionais no atual cenário da sociedade informacional e o papel da Matemática como linguagem e base do desenvolvimento tecnológico. Assim, traremos análises de como a Educação Matemática tradicional pode ser entendida, por vezes, como ferramenta de exclusão social.

No segundo tópico, recortando a maioria excluída do acesso aos bens desenvolvidos na atualidade, trataremos o público adulto não escolarizado como reflexo das desigualdades sociais e educacionais no Brasil. Na possibilidade de ingresso à escola, o adulto integra a Educação de Jovens e Adultos (EJA) tendo esse espaço como o das práticas que o levará à conquista da justiça social.

Pontuando a Educação Matemática nessa escola de possibilidade transformadora, o tópico 4 discute os desafios do seu ensino quando busca-se atingir uma dimensão libertadora e democrática. 
Por fim, apresentamos a Educação Matemática Crítica (EMC) como uma privilegiada teoria de reflexão e orientação para um ensino, de fato, transformador (neste caso, com o foco na rotinas da EJA). Na possibilidade de democratizar o acesso ao conhecimento e desenvolver a postura crítica sobre a realidade, o ensino calcado na EMC permite que os adultos em escolarização qualifiquem seus saberes acumulados (pelas práticas sociais vividas) e os usos dos mesmos diante das necessidades cotidianas.

A EMC é entendida, por nós, como caminho significativo para um novo uso da Matemática escolar: esgota-se a visão da Matemática excludente para o surgimento de uma disciplina que pode redefinir a condição de cidadania e consumo do aluno, tornando-o consciente e livre - como é entendido no contexto pedagógico - da opressão ${ }^{1}$.

\section{A EDUCAÇÃO MATEMÁTICA NA ESCOLA QUE EXCLUI: REASCENDENDO UM DEBATE}

Resgatemos, com outras palavras, a questão levantada no início deste trabalho: será que a escola prepara todo o seu público para os impactos do mundo atual ou privilegia a educação de grupos menores que formarão a nova classe dirigente? E mais: de que maneira a escola deve organizar suas práticas sob uma perspectiva democrática - onde todos possam conhecer, de fato, o mundo em que vivem - em vez de manter a disciplina que formata sujeitos obedientes?

Em "Vigiar e Punir", Foucault (1999) correlacionou o trabalho das escolas com o que acontece dentro das prisões, evidenciando um trabalho estratégico de controle e disciplina.

A disciplina "fabrica" indivíduos; ela é a técnica específica de um poder que toma os indivíduos ao mesmo tempo como objetos e como instrumentos de seu exercício. Não é um poder triunfante que, a partir de seu próprio excesso, pode-se fiar em seu superpoderio; é um poder modesto, desconfiado, que funciona a modo de uma economia calculada, mas permanente (FOUCAULT, 1999, p.143). 
A essa disciplina interliga-se a satisfação dos interesses políticos de manutenção do fosso entre a formação da elite detentora do conhecimento pleno - criadora de novas técnicas, estimuladora de consumo e manipuladora de dados quantitativos - e da massa pouco informada, submissa e controlada - usuária limitada das técnicas, consumidora acrítica e leitora funcional dos dados quantitativos.

Diante desse paralelo, dirigimos as reflexões para o papel da (Educação) Matemática na ação de oprimir ou conscientizar os membros de uma sociedade cada vez mais desenvolvida e abastecida pela linguagem científica.

Skovsmose (2007) discute o quanto as práticas da Matemática escolar podem ser responsáveis por formar sujeitos disciplinados, técnicos, que pouco reconhecem as aplicações verdadeiras e essenciais da ciência na vida real. Sendo ainda mais enfático, levanta a questão da inclusão e da exclusão na sociedade informacional, dizendo que "muitas causas se interconectam. Mas as salas de aula de Matemática podem ser um importante lugar a ser considerado" (SKOVSMOSE, 2007, p. 67).

O que Skovsmose considera ser inclusão e exclusão na sociedade informacional vem a ser a plena ou limitada ação cidadã no mundo de hoje; o grau de interferência na realidade a partir do conhecimento que se tem dela.

Sobre as relações entre Matemática - suas aplicações - e o mundo atual, o cientista Filipe Duarte Santos, em texto publicado na coluna do jornal virtual Público (Portugal, 2014), coloca:

Hoje em dia não há praticamente nenhum domínio da actividade humana que não beneficie do suporte indispensável das aplicações da matemática. As ciências sociais e humanas estão a recorrer progressivamente à estatística, à teoria das probabilidades, à teoria dos jogos, à matemática da optimização, aos sistemas dinâmicos e de um modo geral às equações diferenciais para simular o

\footnotetext{
${ }^{1}$ Os termos opressão e conscientização, usados como base para as reflexões apresentadas neste texto, foram trazidos à luz dos estudos em Educação pelo pedagogista Paulo Freire nos pensamentos expostos inicialmente em Pedagogia
} 
comportamento e a evolução dos sistemas socioeconómicos e socioecológicos (SANTOS, 2014).

Reverberando o dito e voltando ao cenário educacional, a pauta do trabalho com Matemática na escola deve estar comprometida com a utilidade e aplicabilidade dos seus conteúdos. O fato é que, muitas vezes, as metodologias adotadas pouco permitem essa vertente prática, conduzindo um trabalho mecânico, enfadonho e sem qualquer proximidade com a realidade.

Programas desagradáveis e cansativos são característicos de um modelo tradicional de aulas de Matemática (SKOVSMOSE, 2007). Os alunos recebem uma overdose de exercícios, realizam tarefas mecânicas em prazos estipulados pelos seus professores e são examinados para uma medição técnica do quanto assimilaram (ou memorizaram) de todos aqueles processos. Nessas mesmas aulas encontra-se três grupos de alunos: os de excelência (que possivelmente são vistos pelos seus professores como os de brilhante futuro), os normais (que desempenham razoavelmente as tarefas determinadas) e os problemáticos (que manteriam suas dificuldades ano após ano e, quem sabe, evadiriam da escola pela dificuldade apresentada).

Esses alunos normais podem avançar na escolarização e/ou ingressarem em tarefas profissionais onde encontrarão pouca Matemática na sua versão tradicional (SKOVSMOSE, 2007). Ainda assim, se tornando assistentes de lojas, vendedores, fiscais de impostos, motoristas de ônibus, técnicos de laboratório, empregados industriais, dentre outros, será possível ver a influência da Educação Matemática (tida por eles) no seu desempenho. As longas sequências de exercícios e cumprimento de prazos característicos do ensino tradicional são interpretados na sequência de ordens que esses novos profissionais precisam seguir (Ibid.).

Sob a dimensão segregacionista da Educação Matemática, os profissionais citados por Skovsmose são disciplinados a cumprir mandamentos de seus ex-colegas de classe: os alunos de excelência que integram o novo grupo de comando.

do Oprimido (1974) e continuados em Conscientização: Teoria e Prática da Libertação (1980). 
Diante desse entrecho, é surpreendente perceber que a maioria das descrições e orientações para o ensino de Matemática atem-se a uma proposta inovadora, de contextualização e potencializadora da criatividade, resolução de problemas e comunicação. Nada obstante, essas propostas estão longe da realidade da maioria das aulas de Matemática.

Temos que estar conscientes da possibilidade, fortemente indicada por Bourdieu, de que as funções políticas e sociais reais de uma educação matemática particular não dependem, diretamente, da parte oficial do currículo, mas também do contexto social e político em que a escolaridade tem lugar. Embora o currículo da matemática possa ser descrito em certos termos atraentes, a função sociopolítica real de conduzir os estudantes por esse currículo poderia produzir e legitimar uma "nobreza de estado" [...] A educação matemática poderia não apenas designar a "nobreza de estado", mas também ajudar a identificar os "funcionários de estado" (SKOVSMOSE, 2007, p. 37).

Determinar o sucesso de uns e o fracasso de outros poderia ser o grande triunfo do ensino tradicional. Os fracassados serão dispensados sob uma importante lição: "a matemática não é para eles" (Ibid., p.38). Silenciar um grupo de pessoas dessa maneira pode servir a uma função políticosocial e econômica.

As questões que movem as reflexões, aqui, tendem a ser bastante angustiantes quando pensamos nas novas gerações - em escolarização - que se preparam para o mundo posto; um mundo, por vezes, ainda desconhecido em sua complexidade.

Porém, considerando a multiplicidade formadora da escola, um público distinto surge ressignificando ou redefinindo as perguntas levantadas até então; um público que já carrega o peso da exclusão social e da opressão exercida na interrupção de sua plena cidadania. Falamos dos adultos não escolarizados que (re)ingressam à Educação Básica pela crença na recuperação dos direitos que lhe foram negados e na qualificação para a nova organização da sociedade; falamos no público da Educação de Jovens e Adultos, a EJA. 


\section{O JOVEM E O ADULTO OPRMIDOS E A CONSCIENTIZAÇÃO: O FATO E A MUDANÇA NA EJA}

A Educação de Jovens e Adultos - EJA - é uma modalidade de ensino da Educação Básica que pode ser entendida, no caso do Brasil, como assegura Fonseca (2007), muito mais como um símbolo da exclusão social do que propriamente como a possibilidade de escolarização de uma população social e economicamente desenvolvida.

A Educação de Jovens e Adultos é um direito constitucional, mas a escolarização não chegou a todos os brasileiros. Esta realidade tem a ver com um país que, desde o início, foi bastante injusto com os que com seu trabalho construíram as riquezas da nação e que não viram distribuídas essas riquezas acumuladas (CURY, 2004, apud MEDEIROS, 2009, p. 88).

Sob uma análise sócio-histórica, a existência da EJA representa uma tentativa de tratar as cicatrizes históricas do sistema público brasileiro (HADDAD, 1994): um sistema opressor e socialmente desigual.

É aluno da EJA aquele que não teve a oportunidade de frequentar a escola no tempo certo e que, agora, tenta buscar soluções para uma vida marcada pela limitação do acesso aos bens culturais e materiais produzidos pela sociedade. A escola simboliza, para esse sujeito, a possibilidade de ascensão social e conquistas de melhores condições de vida e trabalho. Reconhecer essa expectativa dá à escola a responsabilidade de amenizar as perdas e libertar o aluno de suas privações sociais. Essa libertação não é um mecanismo da escola. É consequência da tomada de consciência crítica do sujeito que se convence da luta pela mudança do quadro social que integra (FREIRE, 1985). Assim, resultado da ultrapassagem da esfera espontânea de apreensão da realidade para chegar a uma esfera crítica na qual "a realidade se dá como objeto cognoscível e na qual o homem assume uma posição epistemológica" (Id., 1982, p. 26).

É a realidade dada como objeto de conhecimento que permite ao homem jovem e adulto a ressignificação de seu mundo e de suas próprias características; o posicionamento diante da realidade em um novo formato de cidadão e trabalhador. Eis a conscientização. 
A conscientização é, neste sentido, um teste de realidade. Quanto mais conscientização, mais se 'desvela' a realidade, mais se penetra na essência fenomênica do objeto, frente ao qual nos encontramos para analisá-lo. Por esta razão, a conscientização não consiste em 'estar frente à realidade' assumindo uma posição falsamente intelectual. A conscientização não pode existir foram da 'práxis', ou melhor, sem o ato ação - reflexão. Esta unidade dialética constitui, de maneira permanente o modo de ser o de transformar o mundo que caracteriza os homens (FREIRE, 1982, p. 26).

Conscientização não é a simples tomada de decisão, mas o seu desenvolvimento crítico (FREIRE, 1982). É a posse da realidade sob o olhar mais crítico possível, conhecendo os "mitos que enganam e que ajudam a manter a realidade da estrutura dominante" (Ibid., p.29).

No contexto da sociedade informacional, a criticidade do aluno jovem e adulto enfrentará o inacesso aos bens materiais e tecnológicos desenvolvidos na atualidade e os massacres do consumo desenfreado e do poder inabalável do marketing.

[...] nunca as mercadorias tiveram seu consumo tão descontrolado e, ao mesmo tempo, tão desigual; [...] a exclusão e a privação são uma constante para imensos contingentes da população do planeta; o acesso aos aparatos tecnológicos sofisticadíssimos é um privilégio para poucos e, ao mesmo tempo, um objeto de desejo para muitos; as possibilidades de satisfação pessoal de lazer e de alegria são ampliadas e diversificadas para algumas camadas da sociedade e negadas a outras tantas (BARCELOS, 2012, p. 24).

Reiterando o discurso de que a Matemática se configura como linguagem e base de desenvolvimento dessa nova sociedade - de tecnologia e consumo arraigados - a discussão recai sobre os compromissos da Educação Matemática diante do imediatismo de um público que possui, neste cenário, intensas relações pessoais e de trabalho.

[...] a educação matemática pode ser vista como a base da sociedade tecnológica;

[...] ela fornece formas de conhecimento e técnicas de particular relevância para a sociedade informacional; [...] a aprendizagem matemática está intimamente 
relacionada com o desenvolvimento de competências para manipulação de tecnologias de comunicação e de informação (ICT) (SKOVSMOSE, 2007, p. 67).

Por uma perspectiva de escola transformadora e em contraposição ao discurso que caracteriza o ensino tradicional de Matemática como ferramenta de exclusão e manipulação, surge uma Educação Matemática libertadora: ela pode ser elemento indispensável para o processo de conscientização do aluno adulto - trabalhador e consumidor.

\section{DESAFIOS E POSSIBILIDADES PARA O ENSINO DE MATEMÁTICA NA EDUCAÇÃO DE JOVENS E} ADULTOS

O aluno da Educação de Jovens e Adultos sofre prejuízo quanto ao exercício pleno de sua cidadania por não dispor, dentre outros, de conhecimentos essenciais para a leitura de dados presentes em situações cotidianas que demandam a tomada de decisões (FONSECA, 2007); de conhecimentos matemáticos sistematizados que tornem mais inteligível a linguagem da sociedade capitalista e informativa.

É importante considerar que a aquisição do conhecimento matemático, pelo aluno adulto, não se dá apenas quando ele inicia ou retoma sua vida escolar. Essa aquisição acontece ao longo de sua vida, quando ele desenvolve, nas práticas cotidianas (principalmente ligadas ao seu trabalho), saberes para a superação de necessidades (DUARTE, 2009).

Assim, tratando do ensino de Matemática, reconhecer os saberes acumulados pelas práticas sociais (pessoais e de trabalho) que os alunos trazem ao espaço de aprendizagem escolar é ação fundamental.

[...] para jovens e adultos, a questão pedagógica mais instigante é o fato de que eles quase sempre, independentemente do ensino sistemático, desenvolvem procedimentos próprios de resolução de problemas envolvendo quantificações e cálculos. Há jovens e adultos analfabetos capazes de fazer cálculos bastante complexos, ainda que não saibam como representá-los por escrito na forma convencional, ou ainda que não saibam sequer explicar como chegaram ao 
resultado [...] (BRASIL, 2001, p. 32).

O valor dado ao conhecimento prévio permite que o aluno reconheça que muitos dos saberes que utiliza no dia a dia são conhecimento matemático e que seu desenvolvimento permitirá a aquisição de saberes mais elaborados - o que qualifica e/ou amplia as capacidades de intervenção em sua rotina pessoal e de trabalho.

Dessa forma, há a necessidade de se desenvolver uma metodologia de ensino que possibilite "a real superação-incorporação do conhecimento que ele já adquiriu, e não uma metodologia que meramente justaponha, ao que o indivíduo já sabe, aquilo que ele não sabe e precisa saber" (DUARTE, 2009, p. 17-18).

O sucesso dessa metodologia existe na convivência entre o saber e a realidade em um programa que se desprende de teorizações desnecessárias. Para Gadotti (2002, p. 32),

um programa de educação de adultos [...] não pode ser avaliado apenas pelo seu rigor metodológico, mas pelo impacto gerado na qualidade de vida da população atingida. A educação de adultos está condicionada às possibilidades de uma transformação real nas condições de vida do aluno-trabalhador.

Em consonância ao dito estão os documentos e materiais didáticos oficiais que referenciam e orientam o currículo escolar para a EJA (dentre eles a Proposta Curricular para o Ensino Fundamental - 2001 - e Cadernos da EJA $-2006^{2}$ ) propõem um ensino ligado às necessidades reais dos alunos e aos seus conhecimentos de vida.

Acontece que não são raras as situações observadas (e aqui baseamo-nos nas observações feitas enquanto pesquisadores) em que o programa de ensino pouco privilegia uma contextualização dos conteúdos de Matemática, o que, ao contrário, ressignificaria a disciplina no espaço da EJA. Ou então, quando pensadas propostas de reconhecimento e valorização do contexto posto, limita-se à aplicação de conteúdos e/ou procedimentos matemáticos em situações extraídas da realidade.

\footnotetext{
${ }^{2}$ Documentos disponíveis em: http://portal.mec.gov.br/index.php?option=com_content\&id=13536\%3Amateriaisdidaticos\&Itemid=913. Acesso: 04/05/2014
} 
Neste último caso, pode parecer estranha a inquietação. Em correspondência, a mesma é explicada quando se entende que tais práticas permitem, de fato, a leitura de modelos e o uso da Matemática na resolução de problemas simples, porém, pouco favorecem uma criticidade sobre essas mesmas leituras e aplicações; uma tomada de decisões consciente.

Monteiro (2012) narra uma situação em que tal constatação também é feita. Em observação de aula na EJA, na qual foi proposta, por certo professor, a verificação de qual preço de um televisor parecia mais vantajoso, descreve a reação dos alunos diante da subjetividade da ação:

A regra posta pelo professor era identificar o televisor mais barato, apesar dele apresentar na proposta a questão em termos da melhor oferta. Os alunos, atendendo ao enunciado proposto pelo professor, entendem como melhor oferta para a compra da televisão não aquela cujo preço era o mais barato, mas a melhor relação custo benefício. Por isso não fazia sentido dizer a melhor oferta concentrando-se na questão financeira [...]. Entretanto, o professor, centrado em sua prática escolar, não abre espaço para discutir o aspecto levantado por essas senhoras e diz em voz alta no centro da classe: "Pessoal, não interessa o modelo da TV, só o preço" (MONTEIRO, 2012, p. 129-130).

É percebido que pouco foi considerado das observações feitas pelo grupo e sobre os mecanismos que os alunos mostravam usar no cotidiano para resolver o problema. Sem dúvidas a perspectiva da turma é bem mais complexa e, por isso, deveria pautar parte das discussões naquela proposta. É possível afirmar que os questionamentos dos alunos diante da questão trazida pelo professor caracterizam-na como distantes das práticas do dia a dia. Além disso, a observação reitera a então inquietação sobre procedimentos a análises em aulas de Matemática que pouco se entregam às dimensões crítica e subjetiva do aluno.

Essas são dimensões que, dentre outras, devem ser privilegiadas e potencializadas pelo ambiente escolar; dimensões que podem carregar, nas suas buscas por consolidação, os principais desafios atuais do ensino de Matemática na Educação de Jovens e Adultos. 


\section{A POTENCIALIDADE DA EDUCAÇÃO MATEMÁTICA CRÍTICA NA PAUTA DOS TRABALHOS COM A} EJA

Afinada às discussões sobre o papel da Educação na configuração social e reverberando a necessidade das consolidações da criticidade e subjetividade através da Matemática, surge, no cenário de nossas discussões, a teoria da Educação Matemática Crítica, do matemático dinamarquês Ole Skovsmose.

As indicações de Skovsmose são muito afinadas às questões levantadas no início desse texto. Segundo ele, a Educação Matemática deve fazer parte de um processo de democratização do conhecimento, no qual informações e todos os questionamentos sobre elas estejam ao acesso de todos os sujeitos, não privilegiando grupos específicos (SKOVSMOSE, 2010).

O pesquisador sustenta a inovação de sua teoria na discussão da dupla característica da Educação Matemática (relacionada às discussões do primeiro tópico deste trabalho): ainda que seja "parte da comunicação e interação diária" (SKOVSMOSE, 2010, p. 48) - leitura de jornais, práticas comerciais e análises quantitativas - é também "parte do processo universal de produzir exclusão" (Ibid., p. 66). E completa:

Matemática não é somente um mistério impenetrável para muitos mas também, mais do que qualquer outra matéria, foi lançada no papel de um juiz 'objetivo', a fim de decidir quem, na sociedade, 'pode' e quem 'não pode'. E, dessa forma, serve como a 'porteira' que deixa ou não passar pela porta de entrada dos que participarão da decisão produtora de processos da sociedade. Negar algum acesso à participação em matemática é também determinar, a priori, quem irá adiante e quem ficará para trás (VOLMIK, 1994 , apud SKOVSMOSE, 2010, p. 67).

É sobre a necessidade de romper a barreira criada pela Matemática que emerge a Educação Matemática Crítica; sobre os esforços desmedidos para democratizar o acesso e a utilização da Matemática no cotidiano. 
Quanto ao trabalho escolar, os problemas matemáticos devem reconhecer a realidade e cultura individual do aluno, assumindo significado diante das práticas sociais vividas pelos sujeitos de aprendizagem; desvelando a configuração da economia e da própria sociedade. "A Educação deve engajar-se no processo político" (SKOVSMOSE, 2007, p. 19).

O aluno adulto, da EJA, que já manipula com alguma facilidade a linguagem matemática básica, do trivial uso cotidiano, nem sempre posiciona-se de maneira crítica quando faz uso dela. Fazer compras e calcular quanto irá receber de troco não é tarefa complexa como avaliar o custobenefício daquilo que se compra. E é sobre essa dimensão subjetiva que a Matemática Crítica se desenvolve.

Criticar um encarte promocional, duvidar de uma pesquisa estatística, investigar as cobranças de consumo e exigir direitos sobre os equívocos da maquinização dos serviços são tomadas de consciência que propulsionam a libertação do aluno-cidadão-consumidor. É essa postura crítica que o faz sair da sombra em que vivia; que o absolve da manipulação opressora.

A teoria da Educação Matemática Crítica credita uma transformação tanto do aluno quanto do professor. Skovsmose diz que "a Educação Crítica enfatiza que um princípio importante é que os parceiros sejam iguais" (SKOVSMOSE, 2001, p. 17), fazendo referência à Pedagogia Emancipadora de Paulo Freire:

Através do diálogo, o professor-dos-estudantes e os estudantes-do-professor se desfazem e um novo termo emerge; professor-estudante com estudantesprofessores. O professor não é mais meramente o-que-ensina, mas alguém a quem também se ensina no diálogo com os estudantes, os quais, por sua vez, enquanto estão ensinando, também aprendem. Eles se tornam conjuntamente responsáveis por um processo no qual todos crescem. (FREIRE, 1972, apud SKOVSMOSE, 2001, p. 17).

Dessa maneira, Skovsmose defende que é o diálogo entre professores e alunos que garante o desenvolvimento democrático da aprendizagem; é nas colocações das partes que o conhecimento se constrói. Sai de cenário o professor que dirige os processos de ensino. Afinal, se a pretensão é 
desenvolver a consciência crítica do aluno, o mesmo não ocorrerá na imposição daquele que educa, mas na troca e na interrelação de valores e pensamentos.

O ensino de matemática pautado na subjetividade do aluno e no desenvolvimento de postura crítica deve traçar objetivos sobre o mundo vivido, real. Além disso, antes de aprimorar as técnicas de resolução dos problemas possíveis na realidade, deve orientar o seu público a ler o contexto, criticar o fato e saber aplicar o conhecimento.

Um ensino de Matemática que valorize a Educação Matemática Crítica deve fornecer aos estudantes instrumentos que os auxiliem, tanto na análise de uma situação crítica quanto na busca por alternativas para resolver a situação. Nesse sentido, deve-se não somente ensinar aos alunos a usar modelos matemáticos, mas antes levá-los a questionar o porquê, como, para quê e quando utilizá-los (PAIVA; SÁ, 2001, p. 01).

A educação que preza a criticidade não objetiva, apenas, a tomada de consciência sobre a realidade, mas as capacidades de saber como e porquê intervir nela, esclarecendo riscos, vantagens e consequências.

A escola, sob esta ótica, é entendida como "um serviço que educa estudantes a serem cidadãos críticos que podem desafiar e acreditar que suas ações poderão fazer diferença na sociedade" (SKOVSMOSE, 2010, p.65).

A Educação Matemática Crítica - afinada aos termos que fundamentam o título deste trabalho - é entendida, no contexto desta pesquisa, como privilegiada ferramenta de desopressão daquele que não se reconhece cidadão e sujeito de saber; libertadora de quem atou-se por não dispor de ferramentas que permitisse integração e intervenção na sociedade informacional. A revelação maior dessa teoria é a contribuição para uma nova postura sobre a realidade desvelada; é a conscientização. 


\section{CONSIDERAÇÕES FINAIS}

A intimidade entre a Pedagogia do Oprimido e a Educação Matemática Crítica (EMC) não surge ao acaso. Skovsmose se referencia na pedagogia freireana para afirmar o caráter transformador da sua teoria em uso. Na perspectiva de desoprimir (como enunciado neste texto) o aluno adulto diante do mundo técnico e cada vez mais abastecido de informações quantitativas, a Educação Matemática deve estar comprometida com uma questão muito maior que a simples ensinagem de procedimentos.

Acreditamos na Matemática Crítica como caminho para dissolver a tão discutida separação entre os que sabem (e por isso dominam) e os que não sabem (ficando exclusos da plena cidadania). As associações e reflexões levantadas neste trabalho intensificam a nossa defesa por uma ressignificação no ensino de Matemática na escola da EJA. O aluno adulto carrega, consigo, conhecimentos acumulados por suas práticas sociais, entre eles o conhecimento matemático ainda que pouco elaborado. À escola cabe não só o desenvolvimento e sistematização desse conhecimento, mas a reflexão sobre seus usos. A perspectiva crítica do ensino de Matemática na EJA valoriza a subjetividade, entendendo que o que se conhece e se manipula está diretamente ligado a valores e vivências pessoais.

Se partirmos do pressuposto que a criticidade é subjetiva, pensaremos na teoria da EMC como uma proposta além do ensino escolar; como uma ferramenta de desenvolvimento da postura crítica do sujeito. Potencializar a criticidade do aluno jovem e adulto ultrapassa a ação de dinamizar os questionamentos sobre uma realidade que se está conhecendo. Trata-se do desvelamento de um mundo informacional - e que tem Matemática como uma de suas principais bases - que era vivido numa condição de obediência e opressão. Assim, a crítica passa a ser uma nova postura diante desse mesmo mundo: a ação livre e consciente sobre as relações pessoais, de trabalho e de consumo. 


\section{REFERÊNCIAS}

BARCELOS, Valdo. Educação de Jovens e Adultos: Currículo e Práticas Pedagógicas. 3. ed. Petrópolis, RJ: Vozes, 2012.

BRASIL, Ministério da Educação. Secretaria de Educação Fundamental. Educação Para Jovens e Adultos - Proposta Curricular para a Educação de Jovens e Adultos: Primeiro Segmento do Ensino Fundamental: 1a à 4a série. Brasília, 2001.

CORTELA, Mario Sergio. A Escola e o Conhecimento: Fundamentos Epistemológicos e Políticos. 3. ed. São Paulo, SP: Cortez: Instituto Paulo Freire, 2000. (Coleção Perspectiva; 5).

DUARTE, Newton. O Ensino de Matemática na Educação de Jovens e Adultos. 11. ed. São Paulo, SP: Cortez, 2009.

FONSECA, Maria da Conceição Ferreira Reis et al (Org.). Letramentos no Brasil: Habilidades Matemáticas. São Paulo, SP: Ação Educativa, 2004.

FOUCAULT, Michel. Vigiar e Punir: Nascimento da Prisão. 20. ed. Petrópolis, RJ: Vozes, 1999. Tradução de Raquel Ramalhete.

FREIRE, Paulo. Conscientização: Teoria e Prática da Libertação. Uma introdução ao pensamento de Paulo Freire. 4. ed. São Paulo, SP: Moraes, 1980.

FREIRE, Paulo. Pedagogia do Oprimido. 15. ed. Rio de Janeiro, RJ: Paz e Terra, 1985.

GADOTTI, Moacir; ROMÃO, José E. (Org.). Educação de Jovens e Adultos: Teoria, prática e proposta. 5. ed. São Paulo, SP: Cortez, 2002.

HADDAD, Sérgio. Tendências atuais na Educação de Jovens e Adultos no Brasil. In: ENCONTRO LATINO-AMERICANO SOBRE EDUCAÇÃO DE JOVENS E ADULTOS TRABALHADORES. Anais do Encontro Latino Americano sobre Educação de Jovens e Adultos trabalhadores. Olinda, 1993. P.86-108. Brasília: Instituto Nacional de Estudos e Pesquisas Educacionais, 1994, 381p.

MONTEIRO, Alexandrina; MENDES, Jackeline Rodrigues; GUIMARÃES, Maria de Fátima. Sujeitos Governados da EJA: reverberações discursivas nas difíceis relações entre saberes matemáticos. Revista Reflexão e Ação, Santa Cruz do Sul, v. 20, n. 2, p.115-135, jul. 2012.

PAIVA, Ana Maria Severiano de; SÁ, Ilydio Pereira de. Educação Matemática Crítica e Práticas Pedagógicas. Revista Iberoamericana de Educación (Online), v.2, n.55/2, p.1-7, 2011.

SANTOS, Filipe Duarte. A Matemática da Sustentabilidade. Público, Portugal, 10 abr. 2014. Disponível em: <http://www.publico.pt/ecosfera/noticia/a-matematica-da-sustentabilidade1631713>. Acesso em: 17 jul. 2014.

SKOVSMOSE, Ole. Educação Matemática Crítica: A questão da Democracia. 5. ed. Campinas, SP: Papirus, 2010. 